\title{
Mitigating the Impact of Managerial Anchoring: The Case for Management by Committee for Major Corporate Financial Decisions
}

\author{
Chia-Hsing Huang* \\ SolBridge International School of Business, South Korea \\ Prasad Padmanabhan** \\ St. Mary's University, USA \\ Wenqing Zhang ${ }^{* * *}$ \\ SolBridge International School of Business, South Korea
}

Today, firms are facing a globally competitive environment. Against this backdrop, firms can ill afford to make mistakes in their capital budgeting and acquisition decisions. When making major decisions, firms may be faced with additional costs associated with managerial anchoring. Using simulation results, it is shown that firms making off-shoring decisions can be better off using two or more managers when managerial anchoring can lead to significant cost increases. This paper shows the conditions under which management by committee can involve higher incremental costs, but are offset by decreased anchoring costs if managers anchor in different directions. It is also shown that firms cannot completely eliminate the impact of anchoring even if they hire an infinite number of managers. Firms should consider hiring additional managers in instances where major decisions are involved, if the incremental cost of hiring the additional manager is offset by decreased anchoring costs. (JEL: G340, G390)

Keywords: behavior finance, anchoring, manager, financial decision

\footnotetext{
* SolBridge International School of Business, Daejeon, South Korea, Email: koreasing@ solbbridge.ac.kr. ${ }^{\star *}$ Bill Greehey School of Business, St. Mary’s University, San Antonio, TX. USA, Email: ppadmanabhan1@stmarytx.edu. *** SolBridge International School of Business, Daejeon, South Korea, Email: wzhang@ solbridge.ac.kr. (We thank the Guest Editor, Dr. Hersh Shefrin, the Editor, Dr. Panayiotis Theodossiou, and an anonymous referee for valuable comments on earlier versions of this paper. Errors and omissions remain our responsibility).
}

(Multinational Finance Journal, 2013, vol. 17, no. 3/4, pp. 341-369)

(C) Multinational Finance Society, a nonprofit corporation. All rights reserved. DOI: $10.17578 / 17-3 / 4-7$ 


\section{Introduction}

Globalization has forced firms to reduce costs even as they seek markets for their products. Specific cost reduction strategies depend on the nature of the industry, the nature of competition within an industry, and on the efficiency of firm management. For instance, strategic mergers and acquisitions have also been recognized as a cost reduction strategy as well as a survival strategy (Seth, 1990; Lei and Hitt, 1995; Gilley and Rasheed, 2000; Bernile, Lyandres and Zhdanov, 2012). In addition, over the last twenty years, outsourcing of non-core activities and increasingly, off-shoring of these activities, has been recognized as one of the critical methods for cost reduction for global firms. Finally, firms today face the daunting task of seeking new markets and simultaneously looking for efficient production strategies that focus on cost reduction from the outset (Hill 2011).

Cost reduction strategies become less effective if managers entrusted with the management of the process exhibit managerial anchoring. Managerial anchoring refers to the tendency by managers to place excessive weight on a specific numerical reference point (as opposed to objective data) when making decisions. Managers may make decisions based on this numerical anchor, rather than objectively considering other information more relevant to the decision making process. ${ }^{1}$ This tendency can lead managers to exhibit signs of irrationality or behavior that may place self interest above the firm's owner's interests, thereby causing firms to incur additional costs associated with managerial anchoring. Today's competitive environment rewards firms and managers who make the right decisions, and penalizes them for wrong decisions. The literature, through agency theory, has linked management performance to managerial reputation and compensation. ${ }^{2}$ Furthermore, managers with superior (inferior) prior track records may be more

1. It is important to distinguish between "anchoring" bias and "recency" bias. Recency bias is excessive reliance on recent information available to the manager. In this paper, when referring to anchoring bias, it is assumed that managers anchor on a subjectively derived "numerical value" rather than on objective (and more recent) information. We thank the editor for directing our attention to this important distinction. Henceforth, and throughout the rest of the paper, when referring to anchoring bias, it is assumed that managers anchor on a specific subjective numerical value.

2. Costs associated with such conflicts are referred to as 'agency costs'. Since the pioneering works of Jensen and Meckling (1976), there have been numerous papers addressing this issue. 
optimistic (pessimistic) in predicting future cash flows. Pressures to produce results for the firm may increase risk taking behavior for corporate managers, and increase the possibility of decision making based on pessimistic predictions.

Without loss of generality, the paper will focus on one important area, namely those associated with decision making involving off-shoring. ${ }^{3}$ While the model proposed in this paper can be used where major acquisition decisions made (or major capital investment projects undertaken), this paper focuses on off-shoring decisions for the following reasons. First, merger and acquisition decisions occur less frequently then capital budgeting and off-shoring decisions. Since the focus of this paper is on managerial anchoring where managers tend to anchor based on past experiences with decision making, the repeated nature of off-shoring makes it a better candidate for modeling purposes. Second, although capital budgeting decisions can also be repetitive, each capital budgeting situation tends to be generally different than the previous one. In other words, changes in the decision making environment makes each situation relatively unique and managers may be unable to anchor, because past experiences may not be completely applicable to the current decision making situation. However, the off-shoring decision making environment generally tends to have a better experience based history relative to the other two environments. Managerial anchoring is a distinct possibility in this environment, and may prove costly to the firm. Off-shoring also involves other costs (like costs associated with loss of technology), the impact of which can be examined in a managerial anchoring context. These costs have also been shown to be important for off-shoring decisions. Finally, off-shoring has become more established and has become an important source for securing or maintaining competitive advantages in an environment where cost reduction is also important. Hence, this paper focuses on off-shoring as the environment for further analysis of the impact of managerial anchoring on major corporate decisions. However, the conclusions of this model are equally applicable for any major corporate decision making environment.

Numerous academic papers present detailed analysis of the costs and

3. Without loss of generality, the model proposed in this paper can easily be extended to any decision where cost reduction is important, and where managerial anchoring contributes to increased costs. This issue is discussed later in the paper. 
the benefits of outsourcing, and especially off-shoring. ${ }^{4}$ Briefly, from an off-shoring decision theoretic perspective, prediction errors associated with managerial anchoring can have considerable impact on firm value. Traditionally, off-shoring of non-core activities was undertaken to reduce costs, and was not considered important to overall corporate strategy. In recent times, however, and as pointed out by Madison \& Padmanabhan (2005) and others, outsourcing and off-shoring activities have now become an integral component of the corporate strategic equation. This is also evidenced by the increased volume of global off-shoring contracts - they were valued at $\$ 12.1$ billion in 2010 (Overby 2010). ${ }^{5}$ Consequently, managing the off-shoring process efficiently has become critically important for firms competing in a global environment. Managers entrusted with the task of making off-shoring decisions are expected to consider such decisions objectively, in theory. In practice, however, managers can introduce to various extent, elements of subjectivity or irrationality in the decisions related to off-shoring. If so, they may make decisions that can prove costly to the firm. For instance, if managers are overly optimistic (pessimistic), they may accept (reject) negative (positive) net present value off-shoring projects, with detrimental consequences for firm value. Managers can also rely more on their subjective estimates (as opposed to objective estimates) when making off-shoring decisions, a phenomenon referred to as managerial anchoring.

To date, few academic papers have examined the impact on firm value of manager optimism/pessimism related to off-shoring decisions. Notable exceptions include the paper presented in Huang and Padmanabhan (2011) who show, using simulation results, that the firm can lose value if managers anchor. However, they only consider the case where only one decision making manager is involved. If the firm relies on the decision making objectivity of one manager, it can potentially incur huge costs if the manager does not behave objectively. Costs could include direct losses in revenue and profits to indirect losses associated with a decreased competitive position in the industry. In today's global environment, firms can ill afford to assume such losses.

4. Foreign outsourcing (outsourcing to a foreign country) is also referred to as off-shoring. In this paper, both terms are used interchangeably. For a detailed review of this literature, refer to Madison and Padmanabhan (2005), and Madison, San Miguel and Padmanabhan (2006).

5. However, outsourcing activity in recent years has declined slightly from 2009 levels. 
Consequently, firms may be better off relying on two or more managers when making important decisions. This paper explores the conditions under which having additional managers involved in the off-shoring decision making process, pay off. While the incremental costs associated with hiring additional managers can easily be measured, it may be more difficult to measure the benefits. This paper argues that if managers anchor in opposite directions, then the net impact can benefit the firm and offset the costs associated with hiring the additional manager(s). Formally, this paper extends the theoretical model presented in Huang and Padmanabhan (2011) to include cases where there are multiple decision makers. Using simulation, this paper shows that management by committee is preferable when off-shoring costs (as a percentage of total costs) increase and managers are prone to anchoring. However, this paper also shows, using simulation results, that the firm cannot completely eliminate prediction errors induced by managerial anchoring, even if multiple managers are involved in the decision making process.

To summarize, this paper attempts to provide some simulation-based answers to the following questions: a) what is the impact of manager anchoring (as it relates to off-shoring) on firm value when two or more managers make decisions by committee? b) What is the impact of high (low) costs associated with loss of technology and data security on firm value when anchoring by committee is present? c) What is the impact of cash flow uncertainties on off-shoring related firm value in the context of managerial anchoring by committee?

Based on the results presented in the Padmanabhan and Huang (2011) model, it is known that managerial anchoring will increase firm level costs. This paper shows that management by committee can mitigate such costs to the firm, under certain circumstances. Based on the simulation results, we conclude that firms must elect management by committee so long as the expected cost savings from decreased total costs associated with mitigated managerial anchoring is larger than the higher marginal costs of hiring the second manager. This paper also finds these cost savings to be an increasing function of the off-shoring cost/total cost ratio. Furthermore, this paper shows that as the costs associated with loss of technology (or other monitoring costs) increases as a function of total costs, management by committee becomes more important.

The paper is organized as follows. In the next section, this paper presents a brief review of the literature related to 
outsourcing/off-shoring and managerial anchoring that serves as a rationale for the paper. Next, the basic elements of the model proposed in this paper are presented, followed by a discussion of model simulation results associated with the different types of situations discussed earlier. Policy implications of our findings and concluding comments are presented in the last section.

\section{Literature Review and Rationale for the Study}

\section{A. The off-shoring literature}

The vast literature on outsourcing/off-shoring attests to the strategic importance of this task to the firm. Benefits and costs of off-shoring are well documented, and will not be discussed here (for more on this, see Madison and Padmanabhan 2006, Levina and Ross 2003, Clott, 2004, Wonseok, Gallivan and Kim 2006, Dimaggio and Powell 1983, and Hall and Liedtka 2005). The essence of the literature is that off-shoring reduces labor and production costs to the client firm, but it can increase monitoring costs as well as costs associated with risks of loss of technology to the vendor and other firms. ${ }^{6}$ Today, globalization and increased pressures to reduce costs has led firms towards higher levels of off-shoring activity. ${ }^{7}$ For many firms, off-shoring costs represent a significant portion of total operating costs.

Hall and Liedtka (2005) argue that over-reliance on stock options for managerial compensation motivates managers to make investment decisions with high risk/return characteristics, and that include outsourcing and off-shoring decisions. ${ }^{8}$ Using simulation, Huang and

6. Vendor refers to the firm receiving the outsourcing contract, and client refers to the firm outsourcing the contract.

7. For more on the benefits of outsourcing, please see Prahalad and Hamel (1990), Madison and Padmanabhan (2005) and Tompkins (2005).

8. Managerial Anchoring has been examined extensively in the behavioral sciences literature. Managers can change their utility functions, behave ethically, or can be driven by emotional and psychological factors. These forces, in turn can force managerial decision making errors. For more on this, see Huang and Padmanabhan (2011), Tversky and Kahneman, 1974, Kahneman and Tversky 1979). Managers can also be subject to availability biases, where they focus on recent (as opposed to more distant) information. In addition, under prospect theory, the loser (winner) tends to become more optimistic (pessimistic) about future profits. These effects have been shown to feed into managerial anchoring, and their 
Padmanabhan (2011) provide evidence that higher levels of managerial anchoring can lead to increased probabilities of decision making errors on the part of the manager. However, they assume that only one manager is responsible for making off-shoring decisions. If off-shoring is gaining strategic importance, firms may consider investing in multiple decision makers when making such decisions. Although multiple managers entail higher incremental labor costs, this paper shows that if decision making managers anchor differently, the benefits of reduced anchoring can offset higher marginal labor costs. This paper extends the analysis conducted in Huang and Padmanabhan (2011) to include multiple managers, and explore the conditions under which managerial anchoring costs are reduced.

\section{B. The managerial anchoring literature}

There is ample evidence that managerial anchoring leads to decision making that are detrimental to shareholders. As presented earlier, managerial anchoring refers to the tendency by managers to place excessive weight on numerical values developed based on subjective initial estimates, as opposed to a reliance on all information relevant for decision making. This tendency is labeled as 'anchoring bias' (Tversky and Kahneman, 1974 and Cudd, Davis and Eduardo, 2006). When managers exhibit anchoring biases, managers develop initial estimates from a variety of possible sources that include their own experiences and subjective beliefs (Tversky and Kahneman, 1974, Uecker, 1978; Sterman, 1989). Managers may then refine these initial estimates, perhaps by combining new objective information with their own subjective probability estimates, to update their beliefs for the following period. According to Tversky and Kahneman (1974), these revised estimates continue to be biased towards their choices of initial estimates. In addition, adjustments made to their initial estimates are shown to be insufficient to force convergence towards the correct values. This tendency by individuals to anchor towards a fixed value (or insufficiently revise their chosen initial value towards the correct value) is referred to as 'phenomenon anchoring' (Tversky and Kahneman, 1974). Managers may believe that their estimates are superior to

practical impacts have been documented extensively in the behavioral sciences literature (Epley and Gilovich 2005, Russo and Schoemaker 1992, Kaustia, Alho and Puttonen 2008, Popescu and $\mathrm{Wu} 2007$, Bromiley 1987). More on the impact of managerial anchoring in an off-shoring context is discussed in the next subsection. 
objective estimates, even if the objective estimates contradict their own subjective estimates. Under the influence of managerial anchoring, there is a tendency of over-reaction and under-reaction in forecast medications (Amir and Ganzach, 1998). The literature documents evidence that professional investors with significant experiences exhibit statistically significant anchoring effects when they develop stock return estimates (Kaustia, Alho, and Puttonen, 2008). The extensive behavioral decision making literature also provides evidence that managerial anchoring can potentially influence investment decision making under uncertainty. Managers may make small adjustments to the anchor and end up with a biased final decision (Tvesky and Kahneman, 1974; Northcraft and Neale, 1987; Whyte and Sebenius, 1997; Latham et. al. 2008). If the investment outlay is large, the company must take steps to ensure that managers make the correct decision based on objective evaluation of data. Managerial anchoring in the context of an unforgiving global economy, coupled with large investment outlays, can prove to be a disastrously deadly combination for the firm.

\section{The Methodology and Model: Maximizing Shareholders' Value with Off-shoring}

This paper utilizes the basic framework used in Huang and Padmanabhan (2011). What follows is a brief description of the methodology (for more details, see Huang and Padmanabhan (2011)). Initially, a simple one period model is developed, where one manager makes an off-shoring vendor selection decision. ${ }^{9}$ The following table outlines the basic parameters introduced in the model (please note that all cash flows are stated as a percentage of end of year revenues, without loss of generality):

$$
C_{0}=\text { Initial cash flows associated with off-shoring, }{ }^{10}
$$

9. It is assumed that the firm has not had any prior experience with outsourcing or off-shoring. We also assume that managers do not change their utility functions during the decision period, nor do they exhibit unethical behavior. They are assumed to maximize expected shareholder value at the end of period 1.

10. In addition, and without loss of generality, we assume that these costs are a percentage of total revenues of the firm for the year. Similarly, all costs referenced in this paper are assumed to be expressed as a percentage of revenues of the firm. 
$C_{u}\left(C_{d}\right)=$ the $P V$ of expected period 1 cash flows, with the subscript $u(d)$ denoting high (low) cash flows

$C_{u u}, C_{d d}, C_{u d}$, and $C_{d u}$ capture cash flows in period 2, uu represents a high cash flow in period 1 followed by another high cash flow in period 2.

It is assumed that manager is interested in maximizing the PV of free cash flows (FCF), as follows: ${ }^{11}$

Free cash flow $=$ EBIT $(1$-tax rate $)+$ Depreciation - Capital Expenditure - Increase in Net Working Capital, Where: EBIT = Revenue - Cost of Goods Sold - Selling, General and Administration Expenses

These variables have the usual connotations. ${ }^{12}$

\section{A. Model Parameters}

This section describes the basic layout. Since this is similar to the layout presented in Huang and Padmanabhan (2011), interested readers are directed to this paper for more detailed information. The cash inflow at time 0 is assumed to be $C_{0}$ and $C_{0}>0$. At time 1 , it is assumed that free cash flow has only two possibilities, $C_{u}$ and $C_{d}$ where $C_{u}>C_{0}>C_{d}$, and $C_{u}=\alpha C_{0}, C_{d}=C_{0} / \alpha, \alpha>1 . \alpha$ captures the ratio of cash flows at time 1 to the cash flow at time $0 .{ }^{13}$ It is further assumed that the actual probability that free cash flow will increase at time 1 is $p\left(C_{u}>C_{0}\right)$. In addition, it is assumed that $L$ (representing $P V$ of costs of possible loss of technology, managerial skill and data security, and expressed as a proportion of initial cash flows; $\left.L=\gamma C_{0}\right) .{ }^{14} \gamma$ can be viewed as the

11. Terminologies used here have the usual accounting definitions.

12. It is assumed that there is no asymmetric information between the company and the outsourcing supplier, discount rate is $0 \%$, taxes rate is $0 \%$ and there are zero risks of bankruptcy. At time 0 , company frees up some units and starts to outsource activities that were conducted in house.

13. Based on the treatment of $\alpha$, higher levels of $\alpha$ also imply higher volatility of cash flows. The implications of this aspect will be explored in a later section.

14. Clearly, data loss/security related issues are more important in off-shoring activities than in outsourcing (domestic) activities. Hence the model considered in this paper is more relevant for off-shoring activities. 
coefficient of loss of technology: a larger $|\gamma|$ represents a higher risk of outsourcing induced technology, managerial skill, and data security loss.

The break even probability when the manager exhibits perfect foresight can be shown to be:

$$
p_{b e}=\frac{-C_{0}-C_{d}-L}{C_{u}-C_{d}-L}
$$

If $p>p_{b e}$, then the project should be accepted. An extension to a two period model, and assuming $L$ to be a constant, the break even probability is as follows: ${ }^{15}$

$$
p_{b e}=\frac{-C_{u}-C_{u d}-L}{C_{u u}-C_{u d}-L}
$$

If $L$ is not assumed constant, the revised breakeven probability can be shown to be:

$$
p_{b e}=\frac{-C_{u}-C_{u d}-\gamma C_{0}}{C_{u u}-C_{u d}-\gamma C_{0}}
$$

The breakeven probability $p_{b e}$ is an increasing function of $|\gamma|$. A single manager's anchoring can lead to higher probabilities (relative to the no anchoring case) of accepting bad projects or rejecting good projects.

\section{Impact of Managerial Anchoring on Firm Value: Revision of Subjective Estimates}

Managerial anchoring can take on new dimensions, in the sense that the manager may only partially anchor. If so, it is assumed that the manager's expected probability $p_{e, t}$ at any time $\mathrm{t}(t>1)$ is a function of the same period breakeven probability $p_{b e, t}$ and the previous (one period) expected probability $p_{e, t-1}$. If $P V_{e, t}$ represents the manager's expected value at time $t$, and is modeled as an independent random variable with

15. For sake of tractability, we assume that a remains constant from period 1 to period 
a systematic component $\eta_{e, t}$ and a random component $\varepsilon_{i, t}$, then: ${ }^{16}$

$$
\begin{gathered}
P V_{e, t}=\eta_{e, t}+\varepsilon_{i, t}=p_{e, t} C_{u}+\left(1-p_{e, t}\right) C_{d}+\varepsilon_{i, t} \\
\text { where: } p_{e, t}=\beta p_{b e, t}+(1-\beta) p_{e, t-1}, p_{b e, t-1}=\frac{-C_{0}-C_{d}-L}{C_{u}-C_{d}-L}, \\
\text { and } \varepsilon_{i, t}=L\left(1-p_{e, t}\right) .
\end{gathered}
$$

Equation (5) is used to capture the phenomenon anchoring concept developed by Tversky and Kahneman (1974). It is assumed that managers maximize $P V_{e, t}$. Managers make their initial decisions using their own subject probability estimates. Managers will combine new objective information with their own subjective probability estimates to update their beliefs for the following period. ${ }^{17}$ As indicated by Tversky and Kahneman (1974), different subjective probability estimate starting points will generate different revised estimates. These revisions tend to be biased toward the initial starting values. $\beta$ is used to capture this propensity - a small $\beta$ suggests that the managers rely more on their own subjective beliefs (which in this case, implies that they rely more on information at time $t-1$, rather than the information at time $t$ ). $\beta$ also captures the phenomenon anchoring coefficient - low $\beta$ represents high levels of anchoring, and vice versa, with $0 \leq \beta \leq 1$. Managerial anchoring can be obviously linked to incorrect off-shoring decisions, and this link has been captured in the Huang and Padmanabhan (2011) paper.

Here, the overestimation (equation 6) and underestimation errors (equation 7) over two periods are described in a more formal manner:

$$
p_{e u}-p_{b e u}=\frac{(1-\beta)(1+\alpha+\gamma)}{\alpha^{2}-1-\gamma}+(1-\beta)\left((1-\beta) p_{e, 0}-\frac{\beta\left(1+\frac{1}{\alpha}+\gamma\right)}{\alpha-\frac{1}{\alpha}-\gamma}\right),
$$

16. It is assumed that $L$ is constant for this part of the analysis.

17. Hence, it is assumed that manager initially anchors to the information available at time $t-1$. As explained earlier, this paper is modeling the anchoring bias exhibited by the manager and not the recency bias (the tendency of the manager to rely heavily on the most recent event (at time $t$ ) and less on previous events (at time $t-1, t-2, t-3 \ldots$ )). 


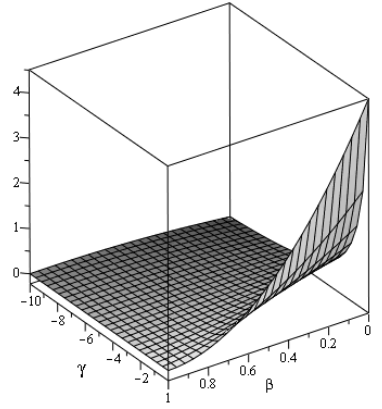

(a). Optimistic Forecasting Errors, $\alpha=1.25$

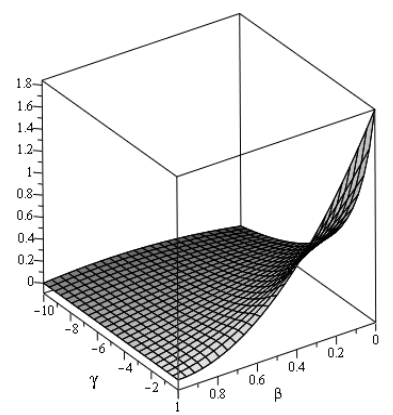

(c). Optimistic Forecasting Errors, $\alpha=1.75$

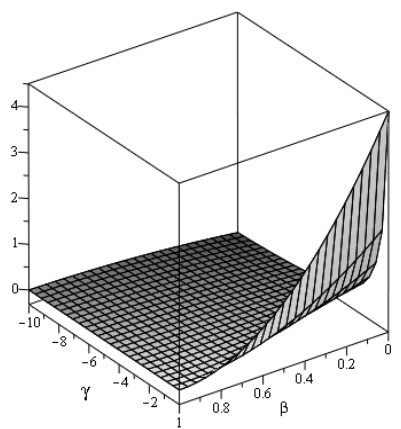

(e). Pessimistic Forecasting Errors, $\alpha=1.25$

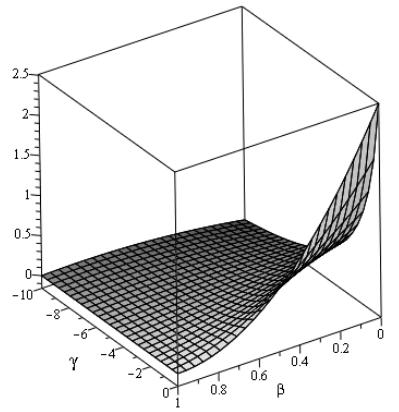

(b). Optimistic Forecasting Errors, $\alpha=1.5$

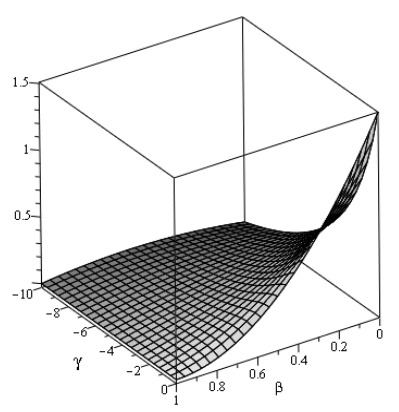

(d). Optimistic Forecasting Errors, $\alpha=2$

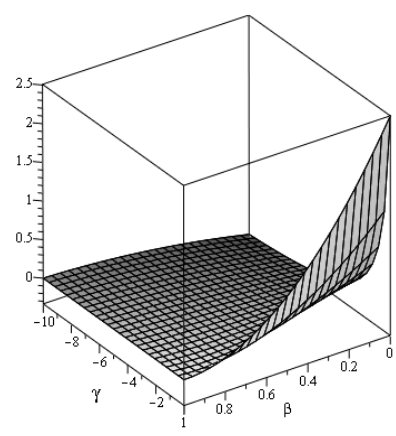

(f). Pessimistic Forecasting Errors, $\alpha=1.5$ 


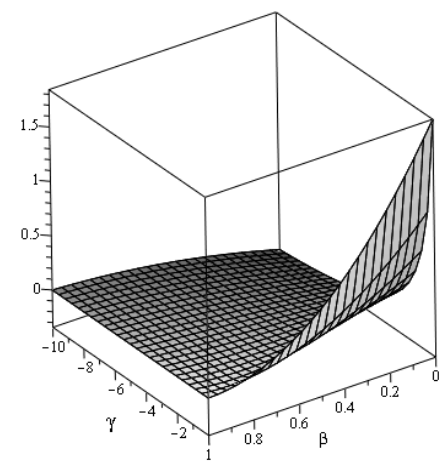

(g). Pessimistic Forecasting Errors, $\alpha=1.75$

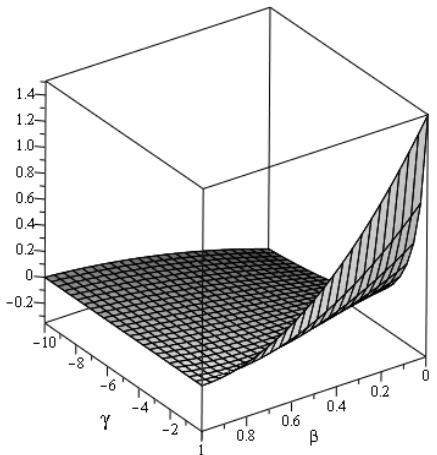

(h). Pessimistic Forecasting Errors, $\alpha=2$

FIGURE 1.- Impact of Manager's Anchoring Effect and Coefficient of Loss of Technology On Off-shoring Decisions

$$
p_{e d}-p_{b e d}=\frac{(1-\beta)\left(1+\alpha+\gamma \alpha^{2}\right)}{\alpha^{2}-1-\gamma \alpha^{2}}+(1-\beta)\left((1-\beta) p_{e, 0}-\frac{\beta\left(1+\frac{1}{\alpha}+\gamma\right)}{\alpha-\frac{1}{\alpha}-\gamma}\right), \text { (7) }
$$

where the difference, $p_{e u}-p_{b e u}$, denotes the optimistic forecasting errors, and $p_{e d}-p_{b e d}$, the pessimistic forecasting errors.

From the expressions for optimistic and pessimistic forecasting errors, captured by (6) and (7), system parameters (such as the trend ratio of cash flows $(\alpha)$, the managerial anchoring effect $(\beta)$, the coefficient of loss of technology $(\gamma)$ ) contribute to the accuracies of the estimates/decisions. Consequently, the impact of changing these parameters on the off-shoring decision errors is examined. The results of these simulations are presented below. The $\mathrm{X}$ and $\mathrm{Z}$ axes represent loss of technology ratio $(\gamma)$ and managerial anchoring effect $(\beta)$. The $\mathrm{Y}$-axis captures forecasting errors for different values of $\gamma$ and $\beta$ for each $\alpha$.

Figure (1) provides an illustration of the impact of $\beta$ and $\gamma$ on optimistic and pessimistic forecasting errors, for different values of $\alpha$. Although the graphs exhibit similar patterns, their shapes are different. When both $\beta$ and $|\gamma|$ become smaller (towards the right hand side of each 


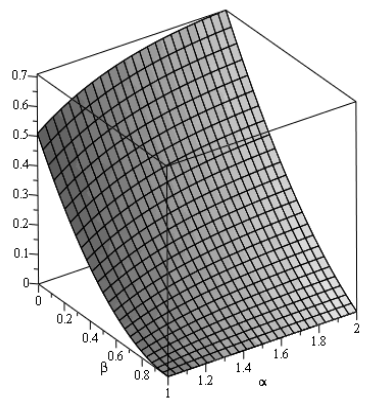

(a). Optimistic

Forecasting Errors, $\gamma=-2$

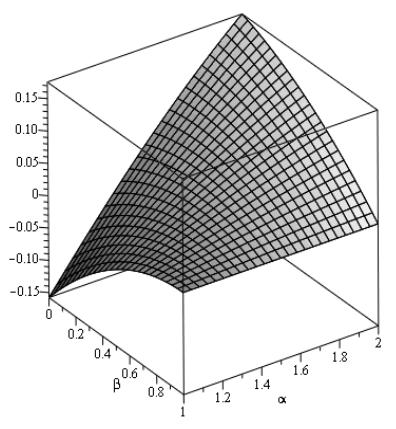

(c). Optimistic Forecasting Errors, $\gamma=-6$

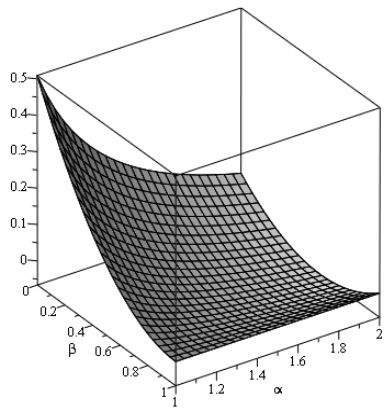

(e). Pessimistic Forecasting Errors, $\gamma=-2$

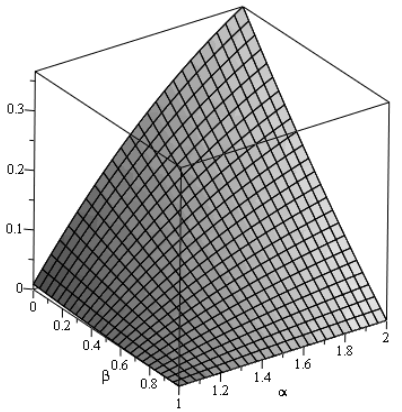

(b). Optimistic

Forecasting Errors, $\gamma=-4$

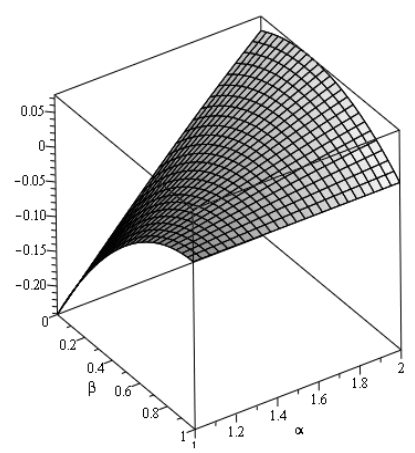

(d). Optimistic Forecasting Errors, $\gamma=-8$

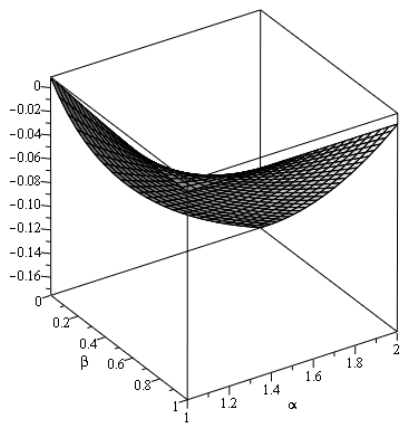

(f). Pessimistic Forecasting Errors, $\gamma=-4$ 


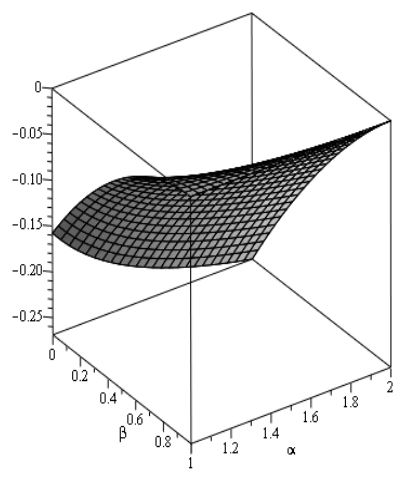

(g). Pessimistic Forecasting Errors, $\gamma=-6$

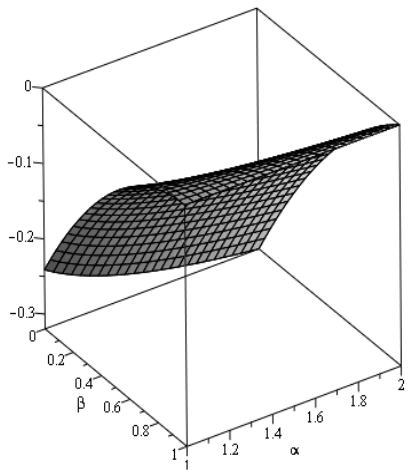

(h). Pessimistic Forecasting Errors, $\gamma=-8$

FIGURE 2.- Impact of Trend Ratio of Cash Flows and Manager's Anchoring Effect On Off-shoring Decisions

graph), the optimistic forecasting errors increases dramatically. If $|\gamma|$ stays large, however, the managerial anchoring effect becomes attenuated. The managerial implications here are twofold. First, if the loss of technology accounts for a significant proportion of total costs (a high $|\gamma|$ ), the costs associated with possible loss of technology dominates the managerial anchoring effect. In this instance, managerial anchoring contributes less to the overall decision. In other words, the manager can anchor a lot, but it may matter little in the overall decision. Second, if $|\gamma|$ is small (less risks associated with losses of technology), managerial anchoring effects dominate other postulated effects in a dramatic fashion, especially when $\alpha$ is small. Similar results can also be found in sub-figures (e) through (h) for positive forecasting errors.

What happens when the cash flow trend ratio is changed? The impact of changing cash flow trend ratios is examined in this section. As figure 2 illustrates, when $\alpha$ increases and $\beta$ decreases simultaneously, both optimistic and pessimistic forecasting errors are amplified in two different directions. If the variance of the cash flows' growth is high and the manager has a strong anchoring tendency, the resulting overall estimates are likely to be incorrect. However, as $|\gamma|$ increases, the joint influence of these two factors (anchoring and variance of cash flows) becomes limited. These findings suggest that if the possibility of loss of 
technology is very high, the other factors lose strategic importance, consistent with our findings reported in figure 1.

Given the contextual importance of the anchoring effect on the firm's financial fortunes, it may want to consider management by committee. The conditions under which the committee method proves beneficial to the firm are explored in the next section.

\section{A. Decision Making By Committee}

The above results were obtained by assuming the presence of only one decision maker. What happens when management decisions are made by committee? ${ }^{18}$ Under certain conditions, it is shown that group decision making can overcome the pitfalls associated with decision making by one manager. Under this scenario, decision makers collaborate to make decisions.

It is assumed that there are $n$ decision makers in our model. Each decision maker independently generates estimates for their subjective probabilities $\left(p_{e u}\right.$ and $\left.p_{e d}\right)$ of future cash flows. The resultant jointly estimated probability estimates (as the arithmetic mean of the individual estimates) are simulated. The individual estimates are shown in equations (8) and (9) for the optimistic/pessimistic managers, respectively.

$$
\begin{gathered}
p_{\text {eui }}=\frac{\beta_{i}(1+\alpha+\gamma)}{1-\alpha^{2}+\gamma}+\frac{\beta_{i}\left(1-\beta_{i}\right)(1+\alpha+\alpha \gamma)}{1-\alpha^{2}+\alpha \gamma}+\left(1-\beta_{i}\right)^{2} p_{e, 0}, \\
p_{e d i}=\frac{\beta_{i}\left(1+\alpha+\gamma \alpha^{2}\right)}{1-\alpha^{2}+\gamma \alpha^{2}}+\frac{\beta_{i}\left(1-\beta_{i}\right)(1+\alpha+\alpha \gamma)}{1-\alpha^{2}+\alpha \gamma}+\left(1-\beta_{i}\right)^{2} p_{e, 0},
\end{gathered}
$$

18. Since management by committee involves management by a team of managers, an important issue is whether team management mitigates or amplifies errors made by a single manager (Shefrin, 2001). Relevant literature documents the presence of a "wisdom of crowds" phenomenon, where estimate derived by aggregation of the judgments made by a group of managers is close to the correct answer (Ariely et al., 2000; Shefrin, 2006; Payne, 2009; Steyvers et al., 2009). The simulation results presented in this paper allows us to determine whether similar conclusions can be made when managers make outsourcing/off shoring decisions by committee. 
where $\beta_{i}$ is the magnitude of managerial anchoring effect for the decision maker $i, i=1,2, \ldots, n$. If all decision makers are optimistic, then the final estimate is given by:

$$
\begin{gathered}
p_{e u}=\frac{1}{n} \sum_{i=1}^{n} p_{\text {eui }} \\
=\frac{1}{n} \sum_{i=1}^{n}\left(\frac{\beta_{i}(1+\alpha+\gamma)}{1-\alpha^{2}+\gamma}+\frac{\beta_{i}\left(1-\beta_{i}\right)(1+\alpha+\alpha \gamma)}{1-\alpha^{2}+\alpha \gamma}+\left(1-\beta_{i}\right)^{2} p_{e, 0}\right) .
\end{gathered}
$$

Similarly the final estimate for all pessimistic decision makers is captured by the following:

$$
\begin{gathered}
p_{e d}=\frac{1}{n} \sum_{i=1}^{n} p_{e d i} \\
=\frac{1}{n} \sum_{i=1}^{n}\left(\frac{\beta_{i}\left(1+\alpha+\gamma \alpha^{2}\right)}{1-\alpha^{2}+\gamma \alpha^{2}}+\frac{\beta_{i}\left(1-\beta_{i}\right)(1+\alpha+\alpha \gamma)}{1-\alpha^{2}+\alpha \gamma}+\left(1-\beta_{i}\right)^{2} p_{e, 0}\right)
\end{gathered}
$$

These probability equations are used to simulate the forecasting errors associated with managerial anchoring when $n$ is increased. To focus attention exclusively on errors generated from managerial anchoring, other system parameters are kept constant. Here, let $\alpha=1.2, \gamma=-5$ and $p_{e 0}=0.509$. In addition, the managerial anchoring coefficient for each manager, $\beta_{i}$, is generated randomly, and bounded by $(0,1)$.

Figure 3 presents simulation results for the two extreme cases where all decision makers either optimistic or pessimistic. In both instances, forecasting errors converge as $n$ increases. An interesting finding is that there is scant evidence to support the hypothesis that forecasting errors can be reduced to zero by the addition of an infinite number of managers (i.e, when $n \rightarrow$ infinity). If managers are either all optimistic/pessimistic, the firm will not benefit by the committee method since they cannot eliminate managerial anchoring errors. In addition, while increasing the number of managers reduces the volatility of forecasting errors, it also increases the incremental costs of hiring additional managers. From the point of view of the firm, this situation is sub optimal. However, the firm may benefit if managers anchor in 


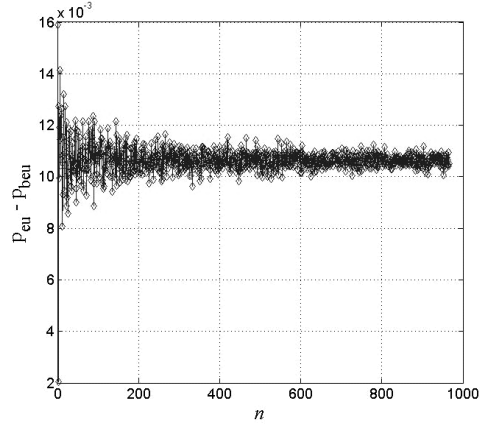

(a). Optimistic Forecasting Errors

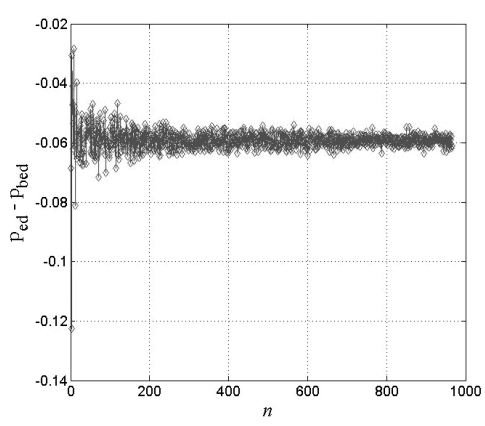

(b). Pessimistic Forecasting Errors

FIGURE 3.- Forecasting Errors When All Decision Makers Are Optimistic or Pessimistic

opposite directions, i.e., when some managers are optimistic while others are pessimistic. This issue is explored in the next section.

\section{B. Decision Making by Committee When Some Managers are Optimistic/Pessimistic}

Assuming that $q$ percent of the original $n$ decision makers are optimistic (and hence 1- $q$ of them are pessimistic), the joint forecasted probability estimates are computed as the weighted averages of the individual probabilities, and are presented below:

$$
p_{e}=q p_{e u}+(1-q) p_{e d}=\frac{1}{n}\left(\sum_{i=1}^{n q} p_{\text {eui }}+\sum_{i=1}^{n(1-q)} p_{e d i}\right)
$$

If the proportion of optimistic decision makers is known in advance, it is relatively easy to postulate the accuracy of their collective forecasting errors. Simulation results when a fraction $q$ percent of managers are optimistic (and 1- $q$ pessimistic) are presented in figure 4 as a three dimensional chart - the $\mathrm{Y}$ axis captures the forecasting errors whereas the $\mathrm{X}$ and the $\mathrm{Z}$ axes represent, respectively, the number of managers $(n)$ and the fraction of optimistic managers in the simulation $(q)$. Other system parameters remain the same as in the previous simulation. For 


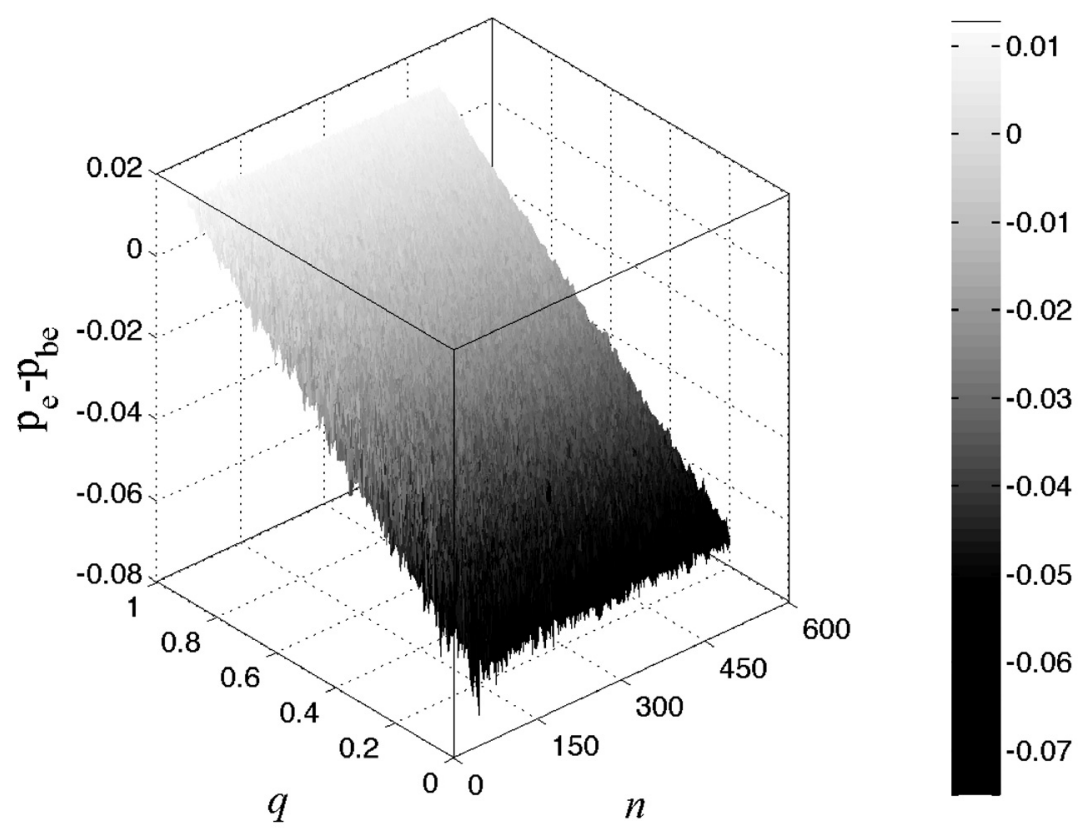

FIGURE 4.- - Forecasting Errors Given $q$ Known

a given $q$, the forecasting error becomes stable (and converges to a fixed point) as the group size of decision makers increases. However forecasting errors cannot completely be eliminated by increasing the group size. This result is consistently observed for all-optimistic/pessimistic cases. In addition, no matter how the weights of previous realized demand and other variables are adjusted, forecasting errors are always present. These results can be attributed to the random nature of the other variables. In this case, although the probabilities of cash flows increasing or decreasing are held constant, the decision characteristics of individual manager (for example, $\beta_{i}$ ) are still random. The good news is that the forecasting error volatility decreases and errors can be predicted with greater precision. Also, when there are more optimistic managers in the sample, the forecasting error tends to be small (i.e. $\left|p_{e}-p_{b e}\right| \rightarrow 0$ roughly before $q=1$ ).

However, the percentage of managers who are optimistic (or equivalently, pessimistic) is not known, a priori. Under these conditions, assuming that $q$ is randomly generated, the net forecasting errors diverge, as presented in figure 5. 


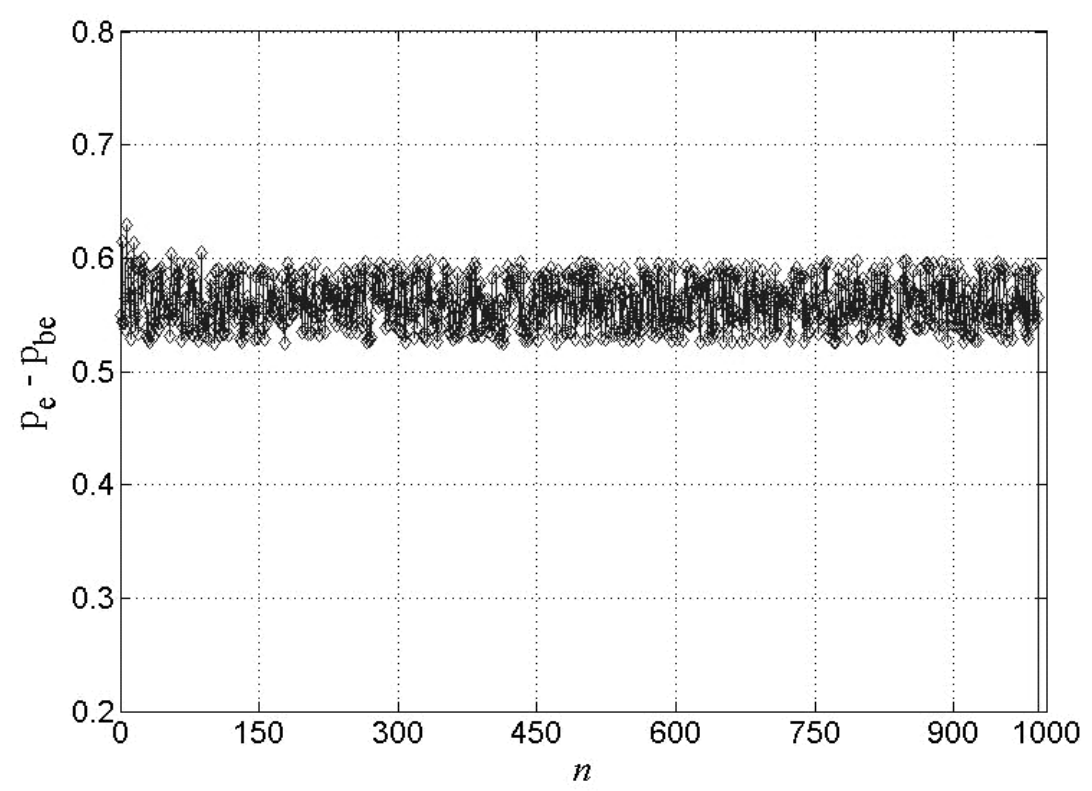

FIGURE 5.- Forecasting Errors Given $q$ Random

These results indicate that management by committee for major off-shoring decisions can reduce the impact of managerial anchoring, and make the resultant estimate closer to the objective forecast. However, not all firms will benefit by the management by committee process. For small firms, managerial anchoring related errors may be insignificant relative to other errors. For larger firms, management by committee makes sense when the off-shoring costs represent a significant portion of total costs, or off-shoring costs are significant in dollar terms. Management by committee also makes sense when there is significant volatility in future cash flows. Even here, the firm must balance the extra incremental costs associated with their involvement in the decision making process against the cost savings from reduced costs due to anchoring mistakes.

From the analysis in the previous section, it is known that the volatility decreases as the number of decision committee members increases. The increase in the number of decision makers, however, cannot guarantee the decrease of errors due to anchoring. Firms can, however, benefit from the limited (and focused) extent of the prediction errors. More specifically, firms can secure more profit as 


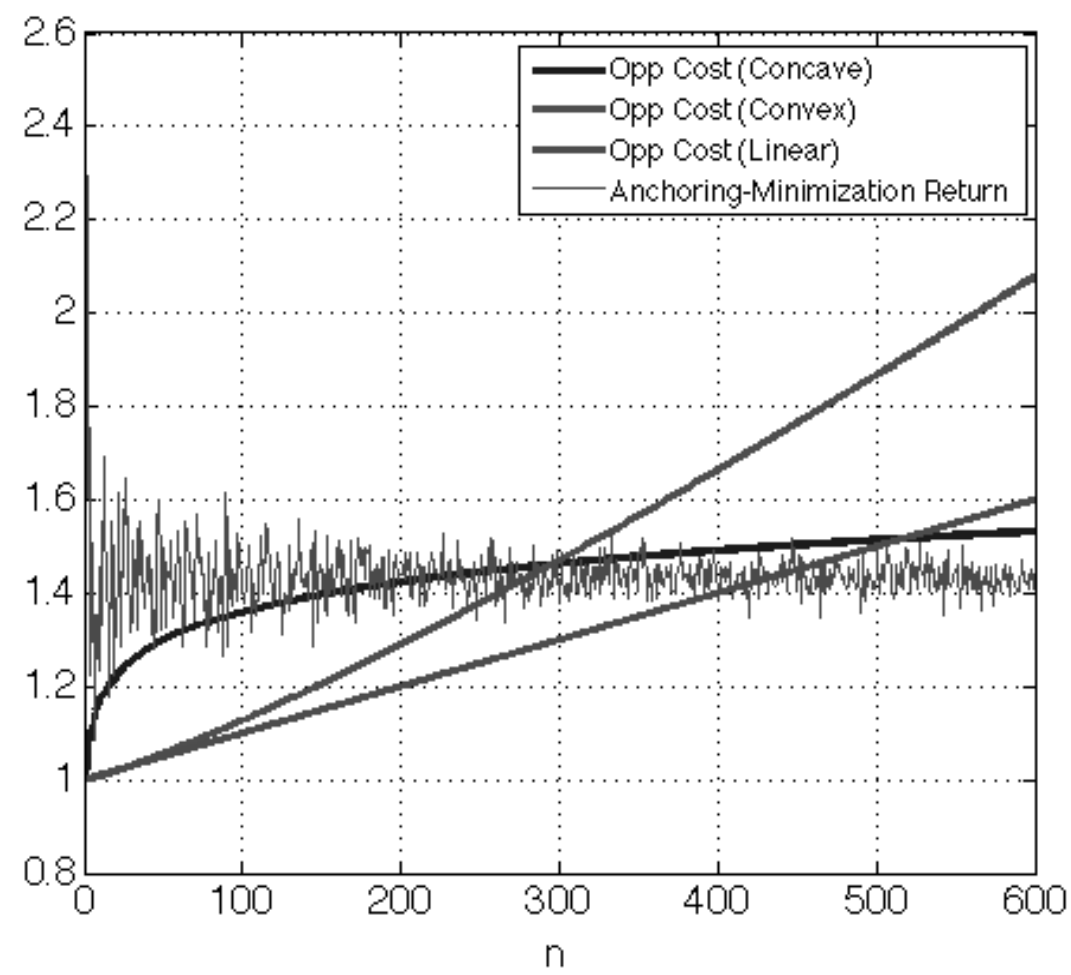

FIGURE 6.- Return from Minimizing Anchoring Effect and Opportunity Costs

$\left|p_{e}-p_{b e}\right|$ decreases. It is now assumed that the profit is a linear function of $\left|p_{e}-p_{b e}\right|$. Increasing the number of decision makers will obviously entail additional costs, either from a need to hire new managers, or from training existing managers. These costs are modeled as opportunity costs and are captured by the cost function of the form $a_{i}+b_{i} n^{\lambda_{i}}$. The cost function can be a concave $\left(\lambda_{i}<1\right)$, a convex $\left(\lambda_{i}>1\right)$ or a linear $\left(\lambda_{i}\right.$ $=1$ ) function of the number of decision makers, $n$, with $a_{i} \geq 0$ and $b_{i}>0$, as shown in figure 6 . The return from anchoring minimization in this scenario is defined as the optimal return minus anchoring costs, as follows: $R=A-c_{e}\left|p_{e}-p_{b e}\right|$, where $R$ is the return, $A$ is the deterministic optimal return, and $c_{e}$ is the coefficient of the forecasting errors. Anchoring costs are therefore modeled as an increasing function of forecasting errors. Hence the net returns (after incorporation of anchoring costs) fluctuates (inversely) with forecasting errors - when 


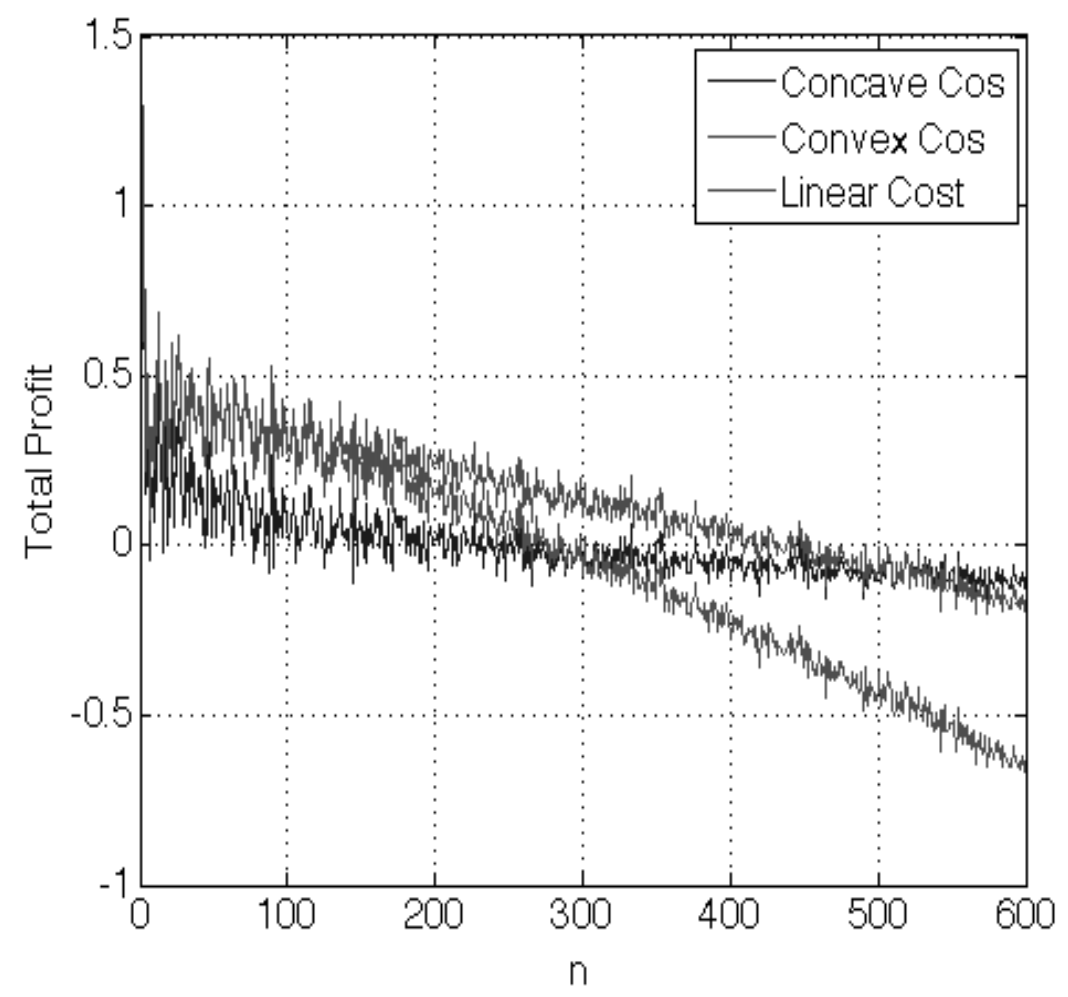

FIGURE 7.- Total Profit with Different Cost structures

forecasting errors go up, the return goes down, and vice versa. More explicitly, figure 7 shows how total profits change as $n$ increases, for the different opportunity cost structures presented earlier. If a trend line for each total profit curve is drawn, the trend lines are unimodal, i.e. they go up at the earlier stage as $n$ increases, but decrease beyond a certain $n$. If returns from anchoring minimization is deterministic (which implies that the total profit curve and the trend line coincide), the optimal value of $n$ can easily be computed. However, because the anchoring tendency of a specific manager is not specified a priori, the optimal value of $n$ cannot be practically determined. ${ }^{19}$

19. Parameters used in figures 6 and 7 are assumed to adopt the following values for illustration purposes - $a_{i}=0, b_{i}=1, \lambda_{i}=\frac{1}{15}$ for concave cost; $a_{i}=1, b_{i}=0.0005, \lambda_{i}=1.2$ for convex cost; $a_{i}=1, b_{i}=0.001, \lambda_{i}=1$ for linear cost, and $A=20, c_{e}=100$. 


\section{Impact of Adding More Managers}

The marginal impact of adding more managers to the decision making process under managerial anchoring is discussed in this section. Suppose $n$ managers are currently in service, $n \geq 1$, and firm management is considering hiring an additional manager with anchoring coefficient $\beta_{n+1}$. Using estimates for the optimistic/pessimistic manager developed in equations (8) and (9), and assuming that a proportion $p$ of the $n$ managers are optimistic, equations (8) and (9) are updated as follows:

If the new manager is optimistic, the updated joint forecasted probability is:

$$
p_{e}=\frac{1}{n+1}\left(\sum_{i=1}^{n q+1} p_{e u i}+\sum_{i=1}^{n(1-q)} p_{e d i}\right)
$$

However, if the new manager is pessimistic, the updated joint forecasted probability is:

$$
p_{e}=\frac{1}{n+1}\left(\sum_{i=1}^{n q} p_{\text {eui }}+\sum_{i=1}^{n(1-q)+1} p_{\text {edi }}\right)
$$

This case is actually nested within the more general case implied in the analysis corresponding to figure 4 . A simple example will serve to illustrate the marginal impact of adding the additional manager. It is assumed that there is currently one manager involved in the decision making process and the manager is optimistic with anchoring tendency $\beta_{1}$. Hence the forecasting error is derived from equation (6). The new forecasting error is $\left|p_{e}-p_{b e}\right|$, where $p_{e}=\frac{1}{2}\left(p_{e u 1}+p_{e d 2}\right)$, with the addition of a second manager (who happens to be pessimistic) with anchoring tendency $\beta_{2}$. Whether the new manager can limit the forecasting error critically depends on the values of the anchoring coefficients $\left(\beta_{1}\right.$ and $\left.\beta_{2}\right)$ that they bring to the decision making process.

It is now assumed that the new manager can only impact cash flow probability and not the other variables. As long as $p_{\text {ed } 2} \leq p_{\text {eu1 }}$, we have $p_{e} \leq p_{e u 1}$, the introduction of the new manager will reduce anchoring induced forecasting errors. This condition is captured in equation (16). A reduction in forecasting error can be guaranteed when the left hand side is greater than (or equal to) the right hand side, i.e. when: 


$$
\begin{gathered}
\left(\frac{\alpha+1+\gamma \alpha}{\alpha^{2}-1-\gamma \alpha}+p_{e o}\right)\left(\beta_{1}^{2}-\beta_{2}^{2}\right) \geq \\
\left(\frac{\alpha+1+\gamma \alpha^{2}}{-\alpha^{2}+1+\gamma \alpha^{2}}+\frac{\alpha+1+\gamma \alpha}{-\alpha^{2}+1+\gamma \alpha}-2 p_{e 0}\right) \beta_{2} \\
-\left(\frac{\alpha+1+\gamma}{-\alpha^{2}+1+\gamma}-\frac{\alpha+1+\gamma \alpha}{\alpha^{2}-1-\gamma \alpha}-2 p_{e 0}\right) \beta_{1}
\end{gathered}
$$

Since $a>1, \gamma<0,0 \leq \beta_{1} \leq 1$ and $0 \leq \beta_{2} \leq 1$, the above condition suggests that there is no guarantee that the left hand side of equation (16) will always be greater than the right hand side. If the above condition holds, then the forecasting error will decrease by the introduction of one more manager in the decision making process. Indeed, whether there is a decrease in forecasting error when two (as opposed to one) managers are involved critically depends on the values of $\alpha, \gamma, \beta_{1}$ and $\beta_{2}$. As an example, if $\alpha=1.45, \gamma=-6.50, \beta_{1}=0.60$, and $\beta_{2}=0.10$ (manager 2 has a lower anchoring coefficient than manager 1 ), then the above condition is met, and the overall forecasting error decreases with the addition of the second manager. However, although forecasting errors can be reduced by hiring the additional manager with preselected anchoring characteristics, the firm may not benefit if the marginal costs of hiring the additional manager is larger than the monetary benefit from decreased anchoring costs. Even here, the above result was derived by placing restrictive assumptions on the other variables of interest, and may not hold for other combinations of the various parameters. In simulation runs using different parameter values, no clear patters were detected for those cases where the acceptance criterion was met. ${ }^{20}$ Even if the anchoring coefficient of manager 2 is lower than that of manager 1 , there is no guarantee that forecasting errors will be reduced, and other behavioral characteristics of the managers may become important. For instance, if both managers are aggressive or conservative, the overall forecasting errors may not be reduced. Careful pre-selection of the second manager given the behavioral predisposition of the first manager may provide a practical

20. Complete simulation results are available on request from the authors. 
way to reduce the impact of managerial anchoring on the off-shoring decision.

\section{Behavioral Characteristics of the Second Manager}

What type of characteristics should the second manager possess? ${ }^{21}$ This discussion is of critical interest in the anchoring based decision making environment. It is clear that the second manager must possess anchoring traits radically different from those of the primary decision maker. If this decision maker is pessimistic and conservative, the second manager should be optimistic and aggressive. However, even apart from the behavioral characteristics of the managers, there are other reasons that can influence the selection of the second manager. For instance, there is considerable evidence that CEO approval is sought whenever firms make large investment outlays (Shivadani and Yermack (1999). Since off-shoring qualifies on this count, it is quite likely that the anchoring traits of the CEO (as the principal decision maker) come into focus. Furthermore, if the CEO is well connected with the board (see for example, Fracassi and Tate (2011)), hiring another board member as the second manager may not achieve the desired result since they are likely to think and anchor alike. ${ }^{22}$ For the firm to benefit from reduced managerial anchoring, the second manager must not come from the board. It may also be desirable to hire an outside consultant, but this may be cost prohibitive. At the very least, the second manager may be from inside the firm, but one who can provide an objective perspective to the current decision.

As the above analyses document, increases in the number of decision makers cannot eventually eliminate anchoring biases completely, even though the firm can benefit from decreased volatility of forecasting errors associated with managerial anchoring. Even with additional managers, the simulation results suggest that there is no guarantee that anchoring effects will always be reduced. Whether a reduction in forecast error is achieved or not critically depends on the values of the

21. We thank an anonymous referee for directing us to this important question and providing us with strong leads in this direction.

22. Fracassi and Tate (2011) also show that a strong CEO - board combination can generate firm level acquisitions that lower firm value and reduce board monitoring. In a managerial anchoring context, hiring an outside manager to oversee off-shoring activities can also serve to increase monitoring activities. 
various parameters as outlined earlier. However, as the simulation results also show, the forecasting errors become more stable as $n$ increases, but do not get reduced to zero. Although firms may be able to predict more accurately the cost associated with managerial anchoring, profiting from this can prove expensive, since hiring more decision makers involves increased marginal hiring costs.

\section{Summary and Conclusions}

First, it is clear that firms can incur substantial costs if managers' exhibit anchoring behavior and these costs are ignored by the firm. With increased global competition, firms can ill afford to accept these losses. A solution is to allow a team of managers (and not rely on one manager) to make off-shoring decisions. Even if one manager exhibits managerial anchoring, the team approach, under certain restrictive conditions, can mitigate any adverse impact on firm value. A team approach is also recommended when there is a greater volatility associated with future cash flows, since managers are prone to make larger prediction errors associated with cash flow volatility. However, higher marginal costs of involving additional decision makers must be balanced against the benefits of lower anchoring costs. Another key insight from the simulation results is that firms can predict more closely the forecasting errors associated with managerial anchoring even if they cannot completely eliminate these errors. Obviously the marginal costs associated with the hiring of additional managers come into play and firms should decide on the optimal balance depending on their cost structures and the importance of getting the off-shoring decision correct. A final insight from formula (16) is that it is extremely difficult to reduce the anchoring error by adding a second manager to the decision making process, even if the marginal costs are not taken into account. Firms may be better off working with one manager and ensuring (via training or by other means) that he or she does not anchor. Another important implication is that the "wisdom of crowds" phenomenon may not always work in an off-shoring/outsourcing context. Indeed, from our simulation results, it is not possible to eliminate the anchoring bias even if an infinite number of managers is added in the decision making process.

Obviously, if the simplifying and restrictive assumptions made during the modeling process are incorrect, the resulting conclusions may 
not be valid. Further research may include the elimination of all or some of these restrictive assumptions. Additionally, the simulations can be carried out with sequential 'learning' on the part of manager committee members.

Accepted by: Prof. H. Shefrin, Guest Editor, January 2013

Prof. P. Theodossiou, Editor-in-Chief, January 2013

\section{References}

Amir, E., and Ganzach, Y. 1998. Overreaction and underreaction in analysts' forecasts, Journal of Economic Behavior and Organization 37:333-347.

Ariely, D.; Au, W. T.; Bender, R. H.; Budescu, D. V.; Dietz, C. B.; Gu, H.; and Zauberman, G. 2000. The effects of averaging subjective probability estimates between and within judges, Journal of Experimental Psychology: Applied 6(2):130-147.

Bernile, G.; Lyandres, E.; and Zhdanov, A. 2012. A theory of strategic mergers, Review of Finance 16(2): 517-575.

Bromiley, P. 1987. Forecast produced by organizations reflect anchoring and adjustment? Journal of Forecasting 6(3):201-210.

Clott, C. 2004. Perspectives on global outsourcing and the changing nature of work, Business and Society Review 109(2):153-170.

Cudd, M.; Davis, H. E.; and Eduardo, M. 2006. Making behavior in repurchase decisions, The Journal of Behavior Finance 7(4):222-229.

Dimaggio, P. J., and Powell, W. 1983. The iron cage revisited: Institutional isomorphism and collective rationality in organizational fields, American Sociological Review 48:147-160.

Epley, N., and Gilovich, T. 2005. When effortful thinking influences judgmental anchoring: Differential effects of forewarning and incentives of self-generated and externally provided anchors, Journal of Behavioral Decision Making 18:199-212.

Fracassi, C., and Tate, G. 2012. External networking and internal firm governance, The Journal of Finance 67(1):153-194.

Hall, J., and Liedtka, S. 2005. Financial performance, CEO compensation, and large-scale information technology outsourcing decisions, Journal of Management Information Systems 22(1):193-221.

Gilley, K. M., and Rasheed, A. 2000. Making more by doing less: An analysis of outsourcing and its effects on firm performance, Journal of Management 26(4):763-790.

Hill, C. W. 2011. Global Business Today, 7th Edition, New York, NY: McGraw-Hill. 
Huang, C.-H., and Padmanabhan, P. 2011. Outsourcing, managerial anchoring, and firm value: A two period model, International Review of Business Research Papers 7(5):16-34.

Jensen M. C., and Meckling, W. H. 1976. Theory of the firm: Managerial behavior, agency costs and ownership structure, Journal of Financial Economics 3:305-360.

Kahneman, D., and Tversky, A. 1979. Prospect theory: An analysis of decision under risk, Econometrica 47:263-291.

Kaustia, M.; Alho, E.; and Puttonen, V. 2008. How much does expertise reduce behavioral biases? The case of anchoring effects in stock return estimates, Financial Management 37(3):391-411.

Latham, G. P.; Budworth, M.; Yanar, B.; and Whyte, G. 2008. The influence of a manager's own performance appraisal on the evaluation of others, International Journal of Selection and Assessment, 16:220-228.

Lei, D., and Hitt, M.A., 1995. Strategic restructuring and outsourcing: The effect of mergers and acquisitions and LBOs on building firm skills and capabilities, Journal of Management 21(5):835-859.

Levina, N., and Ross, J. W. 2003. From the vendor's perspective: Exploring the value proposition in information technology outsourcing, MIS Quarterly 27(3):331-364.

Madison, T., and Padmanabhan, P. 2005. Global economic relationships and outsourcing: The case for privately financed retraining centers, Review of Business Research 5(3):97-105.

Madison, T. F.; Miguel, P. S.; and Padmanabhan, P. 2006. Stock market reaction to domestic outsourcing announcements by U.S. based client and vendor firms, Journal of Information Technology, Cases and Applications Research 8(4):6-24.

Northcraft, G. B., and Neale, M. A. 1987. Experts, amateurs, and real Estate: An anchoring and adjustment perspectives on property pricing decisions, Organizational Behavior and Human Decision Processes 39:84-97.

Overby, S. 2010. IT outsourcing activity remains sluggish in 2010, CIO Magazine, 22 July, http://www.cio.com/article/600261/IT_Outsourcing Activity_Remains_Sluggish_in_2010.

Popescu, I., and Wu, Y.2007. Dynamic pricing strategies with reference effects, Operations Research 55(3):413-429.

Prahalad, C., and Hamel, G. 1990. The core competence of the corporation, Harvard Business Review 68(3):79-91.

Payne, J. 2009. Investment committee decisions: Potential benefits, pitfalls, and suggestions for improvement, Perspectives on Behavioral Finance A Wood (Ed.)

Russo, J. E., and Schoemaker, P. J. H. 1992. Managing Overconfidence, Sloan Management Review 33(2):7-17.

Seth, A. 1990. Sources of value creation in acquisitions: An empirical investigation, Strategic Management Journal 11(6):431-446. 
Shefrin, H. 2001. Behavioral corporate finance, Journal of Applied Corporate Finance 14(3):113-124.

Shefrin, H. 2006. Behavioral Corporate Finance. Chapter 6, New York: McGraw-Hill.

Shivdasani, A., and Yermack, D. 1999. CEO involvement in the selection of new board members: An empirical analysis, The Journal of Finance 54(5):1829-1853.

Sterman, J. D. 1989. Modeling managerial behavior: Misperceptions of feedback in a dynamic decision making experiment, Management Science 35:321-339.

Steyvers, M.; Lee, M. D.; Miller, B.; and Hemmer, P. 2009. The wisdom of crowds in the recollection of order information. In Y. Bengio, $D$. Schuurmans, J. Lafferty, C. K. I. Williams, and A. Culotta (Eds.) Advances in Neural Information Processing Systems, 22:1785-1793. MIT Press.

Tompkins, J. 2005. The business imperative of outsourcing, Industrial Management 48(1):8-13.

Tversky, A., and Kahneman, D. 1974. Judgment under uncertainty: Heuristics and biases, Science 185:1124-1131.

Uecker, W. C. 1978. A behavior study of information system choice, Journal of Accounting Research 16:169-189.

Whyte, G., and Sebenius, J. K. 1997. The effect of multiple anchors on anchoring in individual and group judgment, Organizational Behavior and Human Decision Process 69:75-85.

Wonseok, O.; Gallivan, M. J.; and Kim, J. W. 2006. The market's perception of the transactional risks of information technology outsourcing announcements, Journal of Management Information Systems 22(4):271-303. 